2015-03-06

\title{
Investigating a link of two different types of food business management to the food safety knowledge, attitudes and practices of food handlers in Beirut, Lebanon
}

Faour-Klingbeil, D

http://hdl.handle.net/10026.1/13010

10.1016/j.foodcont.2015.02.045

Food Control

Elsevier BV

All content in PEARL is protected by copyright law. Author manuscripts are made available in accordance with publisher policies. Please cite only the published version using the details provided on the item record or document. In the absence of an open licence (e.g. Creative Commons), permissions for further reuse of content should be sought from the publisher or author. 


\author{
Contact at The University of Plymouth: \\ Dr. Victor Kuri \\ v.kuri@plymouth.ac.uk \\ University of Plymouth. School of Biological Sciences, \\ PSQA410, Drake Circus, Plymouth, PL4 8AA \\ United Kingdom \\ Tel: +44 (0)1752 584600 (Ext.84638) \\ http://www.plymouth.ac.uk/staff/vkuri
}

What follows is a PDF file of a peer-reviewed unedited (author's) manuscript which has been accepted for publication. The manuscript was further subject to copyediting, typesetting, and review of the resulting proof before it was published in its final form. Please note that during the production process errors may have been be discovered which could affect the content, and all legal disclaimers that apply to the journal pertain.

This is an accepted manuscript of an article published by Elsevier Ltd. in

Food Control, 2015, 55, (9):166-175, available at: DOI: 10.1016/j.foodcont.2015.10.024

Article originally published in:

https://www.sciencedirect.com/science/article/pii/S0956713515001383?via\%3Dihub

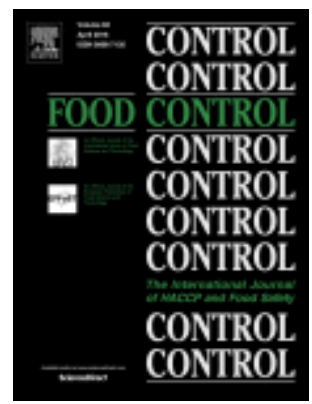

Print ISSN: 0956-7135

Received 23 October 2014

Accepted 24 February 2015

Available online 7 March 2015

Published: April 2016

This is a RoMEO green journal, archived in the institutional repository (PEARL)

Cite this work as:

Faour-Klingbeil, D., Kuri, V., \& Todd, E.C.W. (2015). Investigating a link of two different types of food business management to the food safety knowledge, attitudes and practices of food handlers in Beirut, Lebanon. Food Control, 55 (9):166-175. http://dx.doi.org/10.1016/j.foodcont.2015.02.045

Supplementary data related to this article available from authors and publishers at http://dx.doi.org/10.1016/j.foodcont.2015.02.045

(c) 2015 Elsevier Ltd. All rights reserved

This manuscript version is made available under the CC-BY-NC-ND 4.0 license http://creativecommons.org/licenses/by-nc-nd/4.0/ 


\title{
Investigating a link of two different types of food business management contexts to the food safety knowledge, beliefs and practices of food handlers in Beirut
}

\author{
DimaFaour-Klingbeil $^{\mathrm{a}}$, Victor Kuria, Ewen Todd ${ }^{\mathrm{bc}}$ \\ a School of Biological Sciences, Plymouth University, UK \\ v.kuri@plymouth.ac.uk \\ b Department of Nutrition and Food Science, American University of Beirut, \\ Lebanon \\ c Ewen Todd Consulting, Okemos, MI, USA \\ todde@msu.edu \\ ${ }^{*}$ Corresponding author. dima.faour@gmail.com
}

\section{Highlights}

- Food handlers' knowledge in critical areas of food safety was insufficient

- Training of employees was not found to fill gaps in their knowledge

- The majority of respondents showed favourable agreement to food safety statements

- Food handlers' attitudes were not consistent with their self-reported practices.

- Management type had a significant influence on food safety practices and attitudes

\begin{abstract}
Although Lebanon has a flourishing traditional and modern food businesses, which are typical both Middle Eastern (ME) and Mediterranean cuisines, knowledge and practice of food safety performance of the food service sector are limited in the whole $\mathrm{ME}$ region and lacking in Lebanon. To address this, a survey was conducted in Beirut to evaluate the knowledge, attitudes and practices related to food safety issues of food handlers $(n=80)$ in food service establishments $(n=50)$ and to assess the influence of management type on enactment of safe practices on food premises. Our data suggest that while respondents have limited knowledge of some aspects of food safety, substantial gaps in their knowledge and self-reported practices associated with critical temperature of foods and cross contamination remain, therefore posing health risks to consumer health. Food handlers in corporate managed food outlets showed a significantly higher awareness on food safe practices. It is concluded that the management type is an integral element of TPB (Theory of Planned Behaviour) that influence food handlers' practices and substantiate the need for more research work on safe food handling in the context of food safety culture framework in food businesses. Our data revealed the critical need for food safety education interventions and technical guidance fostered by synergistic participation of the private and public sector to support food handlers in SME's (small and medium sized enterprises).
\end{abstract}




\section{Keywords}

Food handlers; Food safety knowledge; Theory of planned behavior; Food safety practices; Management type

\section{Introduction}

Despite the numerous scientific research and the international authorities' endeavours towards the development of control measures and food safety interventions, food safety remains a global complex public health issue and incidences of food borne diseases persist worldwide.

Data on risk factors for food poisoning outbreaks imply that most incidences result from improper food handling practices in foodservice outlets and homes (Howes, McEwen, S., \& Harris, 1996) and that contaminated hand contacts during preparation of food are probably the common reason of food handlers' implication in most cases. This is often attributed to employees' lack of knowledge (Greig, Todd, Bartleson, \& Michaels, 2007) and to the poor understanding of food management systems which act as principal barriers against the implementation of basic food safety measures in small and medium-sized foodservice companies (SMEs) (Ehiri \& Morris, 1996; Fielding, Ellis, Beveridge, \& Peters, 2005).

The provision of food safety and hygiene training and the effective enactment of safe food handling practices are vital to controlling food-borne illnesses. Better food safety information through training and education of food workers, including their certification, has been shown to improve their food handling practices and reduce food contamination during preparation Hislop and Shaw, 2009, Lynch et al., 2003, McIntyre et al., 2013; Yet, training alone was not proven the only variable correlated with safe and proper practices on food premises. Knowledge plays an essential role in the enhancement of behaviours and practices, but it is not the only factor that would lead to proper food handling and needs to be complemented with other elements (Seaman \& Eves, 2008).

A number of studies used the social cognitive theories to complement the findings on what impedes proper food handling. The Theory of Planned Behaviour (TPB) has been advocated by many researchers to predict determinants of food handler's behaviour (Mullan \& Wong, 2010; Seaman \& Eves, 2010).

According to the TPB, the performance of behaviour is determined by different motivational factors which work together to influence individuals' behavioural intention (Ajzen, 1991), they include attitude, subjective norm (the pressure perceived about whether or not to perform the behaviour as established by social group identity), and perceived behavioural control (perceived availability of opportunities and resources required to perform the behaviour contributing to the perceived ease or difficulty in its performance). Various studies assessed food handlers' knowledge and attitudes.

Whilst several citations assessed the level of knowledge of food handlers on food safety and its influence on beliefs and practices (Abdul-Mutalib et al., 2012; Abdullah Sani \& Siow, 2014; Baş, Şafak Ersun, \& Kıvanç, 2006; Jevšnik, Hlebec, \& Raspor, 2008; Karaman, 2012; Osaili et al., 2013), It was shown that perceived behavioural control (PBC) was the most significant predictor of safe food handling intention suggesting that safe food handling practices are not wholly within food handlers' own control (Mullan \& Wong, 2009).

In Lebanon, as in many developing countries, the food safety regulatory framework through the food supply chain is not effectively developed. One reason for 
this is the antiquated laws responsible for food safety that are not consistent with the international approach that adopts hazard-based and risk-based systems, and overlapping responsibilities of governmental departments and agencies (UNIDO, 2002). This leads to an inadequate enforcement of food law on premises through lack of specific regulations and a limited role for inspections. To date, there is no information on the food safety performance of the food service sector in Lebanon; particularly on the small and medium-sized foodservice establishments which share common challenges, such as the lack of resources (time, labour and financial) and lack of technical expertise (WHO, 2000). Furthermore, there have not been significant contributions of scientific studies on investigating the relation of food businesses management with food handlers' attitudes and behaviour towards food safety.

In this study, we aimed to evaluate the level of knowledge, beliefs and practices in food safety of food handlers in SME's in Beirut, Lebanon, and to assess the influential role of two different types of management (developed corporate owned food businesses and less-developed sole proprietor owned food businesses) as a food safety culture element on their perceptions and safe practices.

\section{Materials and Methods}

\subsection{Sample selection}

There are no official data on the overall number of operating food businesses in Beirut. Many small food businesses are operating without a license of registration as reported to one of us (DFK) by a member in the Ministry of Tourism (MoT). Therefore, a list of 150 foodservice establishments registered in the Lebanese Syndicate of Restaurants owners and the MoT, was formed. The selection of restaurants was based on:

- The business size: micro-small; small; medium

- Types of food served, e.g., raw vegetables salads in addition to other varieties of hot and cold ready to eat foods,

- High business turnover,

- Type of management i.e. local food outlets owned by developed corporations and by less developed sole proprietor or traditional popular food outlets.

The international fast food chains and restaurants and supermarkets were not included in this study.

Restaurants owners/managers were approached by phone to introduce the research objectives and to arrange for an appointment for entry permit to food premises. Out of 150 listed food businesses, 50 restaurants, which represented a geographical portion in Beirut and are typical foodservice outlets in Lebanon and in many countries of the Middle East, agreed to take part in the survey. A greater percentage of the participating foodservice establishments $(70 \%)$ were of micro sized businesses employing less than 10 food handlers, $22 \%$ were small sized with 10-15 food handlers, and $8 \%$ were medium sized food businesses. The survey, including follow up calls and meetings with owners/managers, was carried out over a period of 4 months.

In our study, the term "food handlers" refers to executive chefs, chefs, assistant chefs, owners involved in different functions of food handling i.e. receiving, storing, preparing and cooking food.

\subsection{Development of the questionnaire}

A questionnaire consisting of four sections was designed to be administered in a faceto-face interview with food handlers $(n=80)$ to ensure the accuracy of respondents' 
answers and to avoid external influences. A separate letter of consent for owners and for participant was read explaining the objectives of the research were dually signed by researcher and participants.

- Section one: this was designed to obtain demographic information and each food handler's profile such as gender, age, education, working experience, food safety training course attendance.

- Section two: this contained 17 multiple-choice questions (each with four or five possible answers) and two closed questions to assess food handlers' knowledge on food poisoning, cross contamination prevention, temperature control, personal hygiene, and sanitation. In order to avoid chances that food handlers select correct answers and any answer by chance, the multiple choice answers included "I do not know". The questions were based on the content of a basic level training courses in food safety and adapted from the work of Burcu Tokuç (2009) and Walker, Pritchard, and Forsythe (2003) with some modifications.

Section three: this aimed at understanding food handlers' beliefs on a Likert-type Scale that indicates the degree of agreement of respondents to 16 statements on food safety using a three-point rating scale (disagree $=1$, uncertain $=2$, agree $=3$ ).

The score ranged between 0 and 48 . The sum of scores was converted to 100 points.

Section four: this demonstrated the frequency of safe handling practices. It included 19 questions on sources of personal hygiene, and temperature control, cross contamination prevention, cleaning, storage and display of food on a five points rating scale (never $=1$, rarely $=2$, sometime $=3$, often $=4$ and always $=5$ ). The score range was standardised between 0 and 100 .

The beliefs and practices questionnaires were adapted from the work of Angelillo, Viggiani, Greco, and Rito (2001) with some modifications.

The questions were clearly read to the respondents in a private setting to avoid discomfort or peer and management influence. The interviews took approximately 45 minutes depending on the level of knowledge and education of the interviewees.

\section{Statistical analysis}

All data was analysed using the Windows version of SPSS 21, Statistical Package for Social Sciences.

The knowledge of food handlers was assessed by scoring a correct answer to each question as equal to 1 . The score range was between 0 and 19 . The scores were converted to 100 points. A score below $50 \%$ of food safety knowledge questionnaire is identified as poor knowledge and $50-70 \%$ as limited knowledge considering the percentage of trained respondents. Descriptive statistics were used to summarize the socio-demographic characteristics of respondents and the percent ratio of correct answers. Independent samples $t$-tests were performed to compare selected test parameters between groups. Cross tabulations and chi-square with Fisher's exact tests were used for analysis of associations between tests variables and categorical groups. In some cases, Mann-Whitney U test was used for validation. Results with a p-value $<0.05$ were considered statistically significant.

\section{Results and Discussion}




\subsection{Respondents career background}

The majority of the participants were male (93\%). This seemed surprising since female food workers constitute a higher proportion in studies in other countries (Abdullah Sani \& Siow, 2014; Annor, 2011; Jevšnik et al., 2008; Pichler, Ziegler, Aldrian, \& Allerberger, 2014). This difference might be attributed to different cultures. All of the respondents were involved in the different operational functions from receiving, storing of food as well as in the food preparation and cooking. More than two third of all respondents $(70 \%)$ fell in the range of $21-40$ years of age and the number of head/executive chefs were almost double (38\%) the cooks, assistant chefs or section chefs (Chef de Partie). Only $43 \%$ of food handlers stated that they had attended basic food hygiene or HACCP courses. Almost the third of respondents $(25 \%)$ attained elementary grade compared with none or primary $(13.8 \%)$, high school $(11.3 \%)$ and university graduates (8.8\%). Chi-square analysis showed a significant association of the management environment with the proportion of respondents' education level $(p<0.006)$ and training in food safety $(p<0.002)$. Two third of respondents with hotel management vocational studies (41\%) were employed in the corporate-managed foodservice establishments; Whereas, the majority of respondents with elementary level (85\%) worked for sole proprietor-managed foodservice outlets and restaurants. The reason is that sole proprietor food businesses recruit more of low-educational levels staff as shown in our data and established in earlier study by Clingman (1977).

Similarly, our data showed that two third of food handlers working for corporatemanaged restaurants had received training in food safety compared to one third working for individual owners of food outlets.

\subsection{Overall score of respondents' food safety knowledge}

In general, the respondents on the food safety knowledge questionnaire demonstrated a limited awareness in food safety; even though almost half of the respondents were trained on food safety, the average score of correct answers was $56.6 \pm 21.0$ on 100 score points. The results of this study are comparable to a mean value of $63.2 \%$ reported by Jianu and Chiş (2012) in a study in Romania; and similar to a score obtained from 101 food handlers working in a catering institution (56.5\%) and 335 food handlers working in nursing homes and kindergartens (60.7\%) in Portugal (Martins, Ferreira, Moreira, Hogg, \& Gestal, 2014; Martins, Hogg, \& Otero, 2012). The score was only slightly higher in a Jordanian study by Osaili et al. (2013) who reported $69.4 \%$ total score of correct answers (46.47 out of 67 points). Food handlers who attended formal or informal trainings demonstrated higher capability of understanding the questions. Independent samples t-test revealed a significantly higher overall score on food safety knowledge $(62.5 \pm 21.7)$ of trained food handlers than untrained food handlers $(52.2 \pm 19.6)$. This is consistent with various findings on the empowering impact of training to knowledge (Hislop \& Shaw, 2009; Osaili et al., 2013; Pichler et al., 2014; Soon, Baines, \& Seaman, 2012). However, this significance was not established when the percent ratios of answers of trained and untrained food handlers were compared in the area of temperature control and cross contamination.

The experience of food handlers was also proved to significantly affect the level of food safety knowledge (Lynch et al., 2003; Martins et al., 2012); which is as well demonstrated in our study; the total score of food safety knowledge was significantly higher in food handlers who are working for 10 years or more in the foodservice industry $(64.43 \pm 18.7)$ than in food handlers with less years of experience $(51.1 \pm 20.9)$, and in respondents who occupy higher positions than cook or section chef. This is 
similar to results found by Mclntyre et al. (2013) who conclusively proved that supervisory status and years of experience led to improved knowledge scores in both trained and untrained groups.

Interestingly as well, results indicated significant difference in food safety knowledge scores between food handlers employed by corporate-managed restaurants and by entrepreneurs-managed (sole proprietor) food businesses $(t=2.5$, $\mathrm{df}=78, \mathrm{p}<.016$ ) (Table1). This is explained by our data that highlight a higher proportion of trained food handlers and educated respondents in corporate-managed restaurants. Generally, the food safety knowledge of employees working in food handling in Beirut and elsewhere was proved inadequate which may translate into unsafe food handling practices.

\subsubsection{Knowledge on Safe storage, Temperature of food and Danger Zone}

Almost half $(57.5 \%)$ of respondents did not neither know what the Danger Zone implies nor the range of temperature that is considered optimum for bacterial multiplication. The significant difference between trained and untrained groups was evident $(P<0.001)$ in this specific area as more than two-thirds of trained food handlers $(71 \%)$ reported that they knew what the Danger Zone was. However, when respondents were asked to elaborate more by specifying the range, 69\% supported their answers wrongly compared to a third (31\%) whose identification of the Danger Zone fell in acceptable safe range (between $4^{\circ} \mathrm{C}-6^{\circ} \mathrm{C}$ and $57^{\circ} \mathrm{C}-62^{\circ} \mathrm{C}$ ). This is a concern since we allowed quotes within the ranges of Danger Zone limits from different source US and UK training materials. A greater proportion of the latter percentage of respondents was comprised of trained food handlers who tried to recall the precise Danger Zone range learnt from past trainings. Still, this is a remarkably small proportion relative to the number of trained respondents. Food handlers' knowledge related to temperature control and cross contamination has been proved in various studies to be insufficient (Pichler et al., 2014) and was demonstrated to have a lower score than the overall score on food safety knowledge (Abdullah Sani \& Siow, 2014; Baş et al., 2006; Martins et al., 2014). Only $11 \%$ of respondents in our study identified the correct answer on the hot holding temperature (Figure.1); and half of them were trained (44\%). In our opinion, this represents a major public health concern since temperature control is regarded as a frequent critical control points in food production and foodservice. Food handlers often reflected their inability to comprehend the temperature values and its relevance to the degree of heat. Our data parallels with the findings of Buccheri et al. (2010) and Abdullah Sani and Siow (2014) who reported that $82 \%$ and $82 \%$ of food handlers did not know the critical temperature of storing hot food, respectively.

The proportion of answers varied greatly when respondents were asked for the correct temperature of cooler and freezer units; $77.5 \%$ and $55 \%$ of food handlers knew the correct operation temperature of the refrigerator and freezer, respectively. Whereas less than 50\% were reported to answer correctly by Osaili et al. (2013) and $69 \%$ and $62 \%$ by Jianu and Chiş (2012).

Nearly half $(48 \%)$ were aware of reheating food to $\geq 74^{\circ} \mathrm{C}$, however, untrained respondents $(61.5 \%)$ were clearly selecting the answer key with highest temperature option $\left(80^{\circ} \mathrm{C}\right)$ for the consideration of organoleptic quality of food and customer satisfaction. It is obvious that although trained respondents have significantly higher overall score on food safety knowledge, they demonstrated insufficient knowledge on food temperature requirements. Some were confused by numbers and ranges of temperatures acquired through past trainings, which explains the insignificant difference in the percentage of correct answers when compared to untrained group. 


\subsubsection{Knowledge on Contamination and cross-contamination}

Less than half of respondents (49\%) identified the correct answer on the source of bacterial food contamination. Half of them did not receive any training. Results are consistent with Martins et al. (2012) who showed a significantly lower knowledge scores on questions related to the control of temperatures, personal hygiene and on the sources of contamination than the overall knowledge on food hygiene. The majority of respondents $(95 \%)$ knew that raw and cooked food should be separated, but a third of them believe that this is mainly to avoid retention of the flavour/smell of cooked foods from the raw meat or vice versa.

Misperception of respondents for the reason meat should be thawed on the lowest rack of a refrigerator that contain salads was evident; $34 \%$ of respondents, nearly half of them $(47 \%)$ were trained, believed that the lowest shelf has the least cold atmosphere; hence more effective for thawing frozen meat (Table 2).

Apparently, improved knowledge on the bacterial hazards along the food chain and on the risks of cross-contamination wasn't evident among trained respondents; the results parallels a study by Abdullah Sani and Siow (2014) and Walker et al. (2003) pointed out that this is attributed to the lack of continuous training updates.

\subsubsection{Knowledge on Foodborne disease}

In this study, $77.5 \%$ of food handlers failed to distinguish between food spoilage and food contaminated with pathogens that leads to illness. They considered that changes in taste, smell and appearance will tell if food is contaminated with foodborne disease bacteria. In a previous study by Walker et al. (2003) on food handlers working in small businesses, more than half believed they could tell that food may cause poisoning visually or by taste and smell). Over two third of food handlers (70\%) have a good knowledge of the most frequent common foodborne disease symptoms; the high proportion of awareness on the symptoms of food poisoning were also indicated in several citations (Jianu \& Chiş, 2012; Martins et al., 2012) and in Jordan by Osaili et al. (2013). The most likely reason for this is that foodborne illness is a major health concern and therefore, incidences and symptoms are normally conveyed via media, health campaigns or health practitioners.

\subsubsection{Knowledge on Hygiene and sanitation}

The food safety question with the highest percentage of correct answers was related to hand washing frequency. Almost all respondents (90\%) expressed awareness on the importance of hand washing after touching raw meat and raw eggs, before handling unwrapped ready to eat foods. The results are similar to findings by Manning (1994) and Soares, Almeida, Cerqueira, Carvalho, and Nunes (2012) who indicated that $81 \%$ and $97.6 \%$ of food handlers were aware of the importance of hand washing, respectively. In relation to cleaning and sanitation, two third of food handlers considered that the use of disinfection is the appropriate way to clean knives after use with raw meats. Osaili et al. (2013) reported that $50 \%$ of respondents were aware of washing cutting boards and knives used to cut meat or poultry with hot water or hot water and soap before they use them with vegetables.

In general, training of employees was not found to fill gaps in their knowledge in the aforementioned areas which corroborates with the findings of Soares et al. (2012) and hence, raises concerns on one hand on the quality and relevance of 
delivered trainings and on the other hand on the influence of training intervals on the degree of knowledge retention. In this context, Mclntyre et al. (2013) found food handler knowledge did decrease over time gradually, when trained under a certified comprehensive programme (FOODSAFE), but the loss was significant when measured over a 15 year span, indicating a need for regular retraining sessions. This finding fits with an earlier study by Capunzo et al. (2005) who also showed an improvement after a food safety training refresher course delivered to food handlers on merchant ships, but this did not carry over to a crew change indicating the need for continuous education to maintain safe practices.

\subsection{Respondents' beliefs towards food safety}

\subsubsection{Overall results}

The results showed that respondents have a strong agreement on preventive practices (Figure2). The score of food handlers beliefs was $86.3 \pm 13.2$ over 100 possible points. All respondents believe that they serve safe food to consumers and that training in food safety and hygiene is essential to their work. A great majority agreed that using cap, masks, protective gloves, and adequate clothing reduces the risk of food contamination (96.2\%). These results consistent with studies by Abdullah Sani and Siow (2014) and Buccheri et al. (2010) who reported $93.7 \%$ and more than $90 \%$ of agreement levels, respectively.

Several studies reported good scores of food handlers' attitudes (Abdul-Mutalib et al., 2012; Abdullah Sani \& Siow, 2014; Mclntyre et al., 2013; Soares et al., 2012). However, there were more diverse sets of responses concerning the implementation of temperature control. Almost a third (26.6\%) doesn't consider that measuring the internal temperature of food is important. Furthermore, $22.8 \%$ and $16.7 \%$ agree that thawing meat on the kitchen counter and keeping dishes containing meat for more than 2 hours until it cools down at body temperature is a correct practice, respectively

In regards to hands hygiene, over half $(57 \%)$ of respondents agreed that they should not touch or work with food when they have cuts and abrasions on fingers. This is in contrast to $37 \%$ of respondents who disagreed because of the need to remain on the job due to staff shortages and work pressures. Under these conditions unless properly covered with waterproof bandages, wounds could be infected and then hands become vectors of foodborne pathogens. These figures lead to questioning the measures taken by staff in conditions where hands are vectors of microorganisms to food prepared for consumers and prove that intentions are largely determined by intervening external conditions.

\subsubsection{By type of management and training}

Chi-square analysis showed that the relation of management to food handlers' beliefs approached significance $(p=0.056)$. Mann-Whitney $U$ test validated this finding and showed that distribution of scores on attitudes are not the same across both the management groups $(p=0.005)$. Findings showed that there is a positive agreement concerning the availability of support that facilitates the implementation of the food safety principles in corporate-managed restaurants (85\%) and to a lesser extent in small entrepreneurs-managed food businesses (66\%). However, respondents working for small local businesses run by sole proprietor interpreted "support" as help extended by the head chef who is a role model in that case. In general, the latter group reflected a lack of comprehension of the food safety principles and requirements per se. 
The analysis showed a significant association of food handlers' beliefs with the management environment $(p<0.05)$ in relation to the provision of hand washing facility and to the availability of management support; this significance was also noteworthy in relation to statements related to food temperatures (Table 6). A high percentage of food handlers in corporate-managed food businesses (89.7\%) compared to (50\%) in sole-proprietor managed food outlets agreed that measuring internal temperature of food is important. In the latter group, respondents often indicated that they can tell by experience or touch. Hand washing sinks were accessible to the majority of respondents in corporate-managed group (97\%) but not to one third of respondents in the other group. Such differences between both groups are expected in view of the financial resources of corporate operated premises.

On the other hand, the majority, $93 \%$ and $96 \%$ of respondents in corporatemanaged and sole proprietor-managed businesses respectively, reported that raw food should be separate from cooked food. However, this similarity may not be conclusive evidence on the equivalence of understanding of respondents from both groups in view of the wrong explanation given by half of them when asked for the reason cooked foods should be separated from raw foods (transfer of undesirable odor, taste).

In addition, the results showed no significant difference between trained $(87.9 \pm 16.5)$ and untrained group $(85.1 \pm 10.2)$ with respect to the overall mean scores on food handlers' beliefs. The lack of significance may be due to misperceptions of some respondents who believed they served safe food to consumers while control measures and hygienic conditions were not found adequate.

\subsection{Respondents' food safety practices}

\subsubsection{Overall results}

Proper practices and behavior of food handlers during food preparation is crucial for the health of consumers. Overall, results on self-reported food safety practices reflected a limited level of control measures. The score on self-reported practices was $61.3 \pm 13.6$, with a maximum score of 80.0 (over 100 possible points).

Safe practices related to temperature control were not properly implemented. More than two third of surveyed food handlers(67.6\%) reported that they never measure the temperature of incoming cold or frozen items, further to $75.3 \%$ and $70.8 \%$ who never measure the food temperature during cooling and reheating as well as during cooking, respectively (Figure. 3)."We receive the goods already cold" was often stated. Besides, the temperature of cooling appliances and food display counters were not monitored by $64.5 \%$ and $64.7 \%$, respectively. Respondents often commented :"we look at the external gauge that display the internal temperature for control". The data showed that self-reported practices of respondents were not consistent with their agreement that improper storage of food might lead to health risks.

\subsubsection{By management and training}

Statistical analysis indicated a significant difference in the practices of food handlers in kitchen in relation to training $(t=3.024, d f=78, p<.003)$ and management work environment $(t=3.507, d f=78, p<.001)$. Overall scores of self-reported practices on food safety were significantly higher in corporate-managed group and trained group compared to the overall scores of food handlers in in entrepreneurs-managed and 
untrained group (Table 3). This difference is statistically significant in relation to the mean score on preventive practices relevant to temperature control requirements and sanitation practices (Table 5) and it is substantially reflected with the higher trend of disinfection use noted in corporate-managed group (84.6\%) compared to entrepreneurs-managed group (39.6\%) (Table 4). Our data reinforced that food handling behaviour is not within the person's sole control, and as suggested by the TPB, the more favourable the intentions and subjective norms, and the greater the perceived control the more likely individual's intention are put into action. Hence, motivating working environment and employees satisfaction, availability of management's support and resources are essential elements for the enactment of what have been learnt to ensure safe practices on food premises (Jevšnik et al., 2008; Seaman \& Eves, 2010)

In addition, more than two third of untrained food handlers (80\%) and nearly all respondents working in sole proprietor-managed food businesses (90\%) stated that they never monitor the temperature of received frozen meats products contrary to $45.5 \%$ of trained food handlers and $61.5 \%$ of respondents working in corporatemanaged restaurants who reported frequent "always" monitoring. In spite of this difference, trained food handlers have not reported an appropriate level of safe practices in the kitchen. Only few trained respondents $(25.8 \%)$ monitor the internal temperature of foods during cooking. A great majority of respondents reported that they use separate cutting boards for raw and cooked foods $(89.5 \%)$. The use of disinfectants in the kitchen was reported by only half $(55 \%)$ of the respondents although the majority's opinion obtained in the attitude test was in favor of using sanitizers.

The results on hand washing practices are comparable to those reported by Manning (1994) and Soares et al. (2012); 80.8\% and $89.7 \%$ of food handlers stated that they always wash their hands before and after putting on the gloves, respectively.

While our results reflected that corporate-owned enterprises stresses on personal hygiene and offers advantage of resources to support safe practices, preventive procedures, monitoring tools and systems were lacking overall at the time of this survey. Although the intentions to adhere to safe practices were scored high and were greater in food handlers of this group than their counterpart, safe food handling activities remained inadequate.

In his definition of "Proactive Compliers", a typology of food safety culture which refers to the classification of the different types of food safety culture in food businesses, Wright (2013) stated: "Management provide a lead in encouraging compliance for sake of the business ...but may not go beyond "good practice". Renowned for their branding strategy to expand locally and/or internationally, the corporate group reveals a proactive type of management. The majority employ food safety officers or third party auditors to run a safe operation, yet they seem to have more critical consideration of their business growth in view of the lack of a comprehensive hazard-based food safety system in place.

Our analysis proved that management type has impact on attitudes and can be used as a predictive indicator of food handlers' practices. It implies that compliance to food safety requirements and effective management of food safety risks will be improved in an effective food safety culture of food businesses that could progressively approach "Leadership" by "viewing hygiene as a critical business issue" (Michael, Paul, \& Gill, 2013).

\section{Conclusion}


Our results indicated a limited knowledge and common misperceptions of respondents in crucial areas of food safety i.e. temperature control, cross-contamination hazards that could consequently lead to poor and incorrect hygienic practices, the most common causes for food poisoning outbreaks (Djekic, Smigic et al. 2014).

It was established that food handlers' beliefs were not consistent with their behaviour. Various interfering factors such as misperceptions of "safe and correct practices", the workplace environment and management support influence food handlers' behaviour. Hence, it could well be that respondents carry positive attitudes in every aspects but they may not have intention to put it into practice. Of particular importance, the self-reported practices were significantly associated with the type of management. In the food businesses operated by sole proprietor or owners, the operational functions remain the responsibility of the owner or the chef. In many cases they were found to lack interest or awareness in food safety issues, hence food safety is dependent on human behaviour and different external complex factors, i.e., cultural and social background, limited resources and space, lack of skills and a legislative and institutional framework for food safety control. Whereas in corporate-managed food companies with business orientation for branding and franchising, the food safety operations are structured and food safety depends basically on the business priorities of the management and its perception of risks. The findings of this study confirm the relevance of management type as integral element in the Theory of Planned Behaviour (TBP) for predicting food handlers' beliefs and safe practices.

Our study is the first in Lebanon and among very few in the Middle East region that presents a baseline data for more research on food handlers' behaviours and substantiate future work for assessing traditional food handling practices within the context of organizational values and its perceptions of food safety risks, most importantly within a food safety culture evaluation framework in order to craft effective food safety education and strategy.

The outcomes of this study call for national efforts and reform of food safety policies to leverage the role of local authorities in compulsory training and inspection routines in view of the overlapping mandate between different governmental agencies. It also underlines the obvious need of food handlers in the SME's for ongoing educational support and technical guidance with emphasis on the key role of cultural and social influences on their perceptions, hence knowledge. Such needs might be best approached by a public and well-established private sector partnership aiming at fostering technical and educational support committees for the SME's. Future work will include an observational survey on food handlers' practices in the same surveyed food businesses together with microbiological assessment of raw salad vegetables to investigate the reliability of the self-reported practices and impediments of safe food handling, and to probe microbiological indicators linked to the food safety performance on premises.

\section{Acknowledgments}

The authors gratefully acknowledge the logistics support provided by the Department of Nutrition and Food Science, American University of Beirut. The study was partially funded through a grant from the Lebanese National Council for Scientific Research (CNRS).

The authors also express their appreciation to managers and employees who participated in this research project.

\section{REFERENCES}


Abdul-Mutalib, N.-A., Abdul-Rashid, M.-F., Mustafa, S., Amin-Nordin, S., Hamat, R. A., \& Osman, M. (2012). Knowledge, attitude and practices regarding food hygiene and sanitation of food handlers in Kuala Pilah, Malaysia. Food control, 27(2), 289-293. doi: http://dx.doi.org/10.1016/i.foodcont.2012.04.001

Abdullah Sani, N., \& Siow, O. N. (2014). Knowledge, attitudes and practices of food handlers on food safety in food service operations at the Universiti Kebangsaan Malaysia. Food Control, 37(0), 210-217. doi: http://dx.doi.org/10.1016/i.foodcont.2013.09.036

Ajzen, I. (1991). The theory of planned behavior. Organizational Behavior and Human Decision Processes, 50(2), 179-211. doi: http://dx.doi.org/10.1016/07495978(91)90020-T

Angelillo, I. F., Viggiani, N. M., Greco, R. M., \& Rito, D. (2001). HACCP and food hygiene in hospitals: knowledge, attitudes, and practices of food-services staff in Calabria, Italy. Collaborative Group. [Research Support, Non-U.S. Gov't]. Infect Control Hosp Epidemiol, 22(6), 363-369. doi: 10.1086/501914

Annor, G. A., Baiden, E.A. (2011). Evaluation of Food Hygiene Knowledge Attitudes and Practices of Food Handlers in Food Businesses in Accra, Ghana

Food and Nutrition Sciences, 2, 830-836.

Baş, M., Şafak Ersun, A., \& Kıvanç, G. (2006). The evaluation of food hygiene knowledge, attitudes, and practices of food handlers' in food businesses in Turkey. Food control, 17(4), 317-322. doi: http://dx.doi.org/10.1016/i.foodcont.2004.11.006

Buccheri, C., Mammina, C., Giammanco, S., Giammanco, M., Guardia, M. L., \& Casuccio, A. (2010). Knowledge, attitudes and self-reported practices of food service staff in nursing homes and long-term care facilities. Food Control, 21(10), 1367-1373. doi: http://dx.doi.org/10.1016/i.foodcont.2010.04.010

Burcu Tokuç, G. E., Ufuk Berberoğlu, Esra Bilge, Hasan Dedeler. (2009). Knowledge, attitudes and self-reported practices of food service staff regarding food hygiene in Edirne, Turkey. Food Control 20(6), 565-568.

Capunzo, M., Cavallo, P., Boccia, G., Brunetti, L., Buonomo, R., \& Mazza, G. (2005). Food hygiene on merchant ships: the importance of food handlers' training. Food Control, 16(2), 183-188.

Clingman, C. D. (1977). Foodservice Manager Certification - Nifi Program. Journal of Food Protection, 40(3), 196-197.

Hislop, N., \& Shaw, K. (2009). Food safety knowledge retention study. J Food Prot, 72(2), 431-435.

Howes, M., McEwen, S., G., M., \& , \& Harris, L. (1996). Food handler certification by home study: Measuring changes in knowledge and behavior. Dairy, Food and Environmental Sanitation., 16, 339-343.

Jevšnik, M., Hlebec, V., \& Raspor, P. (2008). Food safety knowledge and practices among food handlers in Slovenia. Food Control, 19(12), 1107-1118. doi: http://dx.doi.org/10.1016/i.foodcont.2007.11.010

Jianu, C., \& Chiş, C. (2012). Study on the hygiene knowledge of food handlers working in small and medium-sized companies in western Romania. Food Control, 26(1), 151156. doi: http://dx.doi.org/10.1016/..foodcont.2012.01.023

Karaman, A. D. (2012). Food safety practices and knowledge among Turkish dairy businesses in different capacities. Food control, 26(1), 125-132. doi: http://dx.doi.org/10.1016/i.foodcont.2012.01.012

Lynch, R. A., Elledge, B. L., Griffith, C. C., \& Boatright, D. T. (2003). A comparison of food safety knowledge among restaurant managers, by source of training and experience, in Oklahoma County, Oklahoma. [Research Support, Non-U.S. Gov't]. J Environ Health, 66(2), 9-14, 26.

Manning, C. K. (1994). Food safety knowledge and attitudes of workers from institutional and temporary foodservice operations. Journal of the American Dietetic Association, 94(8), 895-897. doi: http://dx.doi.org/10.1016/0002-8223(94)92372-8 
Martins, R. B., Ferreira, D., Moreira, L. M., Hogg, T., \& Gestal, J. (2014). Knowledge on food hygiene of food service staff working in nursing homes and kindergartens in Porto region - Portugal. Food Control, 42(0), 54-62. doi: http://dx.doi.org/10.1016/j.foodcont.2014.01.037

Martins, R. B., Hogg, T., \& Otero, J. G. (2012). Food handlers' knowledge on food hygiene: The case of a catering company in Portugal. Food Control, 23(1), 184-190. doi: http://dx.doi.org/10.1016/i.foodcont.2011.07.008

McIntyre, L., Vallaster, L., Wilcott, L., Henderson, S. B., \& Kosatsky, T. (2013). Evaluation of food safety knowledge, attitudes and self-reported hand washing practices in FOODSAFE trained and untrained food handlers in British Columbia, Canada. Food Control, 30(1), 150-156. doi: http://dx.doi.org/10.1016/i.foodcont.2012.06.034

Michael, W., Paul, L., \& Gill, P. (2013). A tool to diagnose culture in food businesses operators - Food Standards Agency research report (F. S. Agengy, Trans.).

Mullan, B. A., \& Wong, C. L. (2009). Hygienic food handling behaviours. An application of the Theory of Planned Behaviour. Appetite, 52(3), 757-761. doi: http://dx.doi.org/10.1016/j.appet.2009.01.007

Mullan, B. A., \& Wong, C. L. (2010). Using the Theory of Planned Behaviour to design a food hygiene intervention. Food Control, 21(11), 1524-1529. doi: http://dx.doi.org/10.1016/j.foodcont.2010.04.026

Osaili, T. M., Abu Jamous, D. O., Obeidat, B. A., Bawadi, H. A., Tayyem, R. F., \& Subih, H. S. (2013). Food safety knowledge among food workers in restaurants in Jordan. Food Control, 31(1), 145-150. doi: http://dx.doi.org/10.1016/j.foodcont.2012.09.037

Pichler, J., Ziegler, J., Aldrian, U., \& Allerberger, F. (2014). Evaluating levels of knowledge on food safety among food handlers from restaurants and various catering businesses in Vienna, Austria 2011/2012. Food Control, 35(1), 33-40. doi: http://dx.doi.org/10.1016/i.foodcont.2013.06.034

Seaman, P., \& Eves, A. (2008). Food hygiene training in small to medium-sized care settings. Int J Environ Health Res, 18(5), 365-374. doi: 10.1080/09603120802272193

Seaman, P., \& Eves, A. (2010). Efficacy of the theory of planned behaviour model in predicting safe food handling practices. Food Control, 21(7), 983-987. doi: http://dx.doi.org/10.1016/j.foodcont.2009.12.012

Soares, L. S., Almeida, R. C. C., Cerqueira, E. S., Carvalho, J. S., \& Nunes, I. L. (2012). Knowledge, attitudes and practices in food safety and the presence of coagulasepositive staphylococci on hands of food handlers in the schools of Camaçari, Brazil. Food Control, 27(1), 206-213. doi: http://dx.doi.org/10.1016/i.foodcont.2012.03.016

Soon, J. M., Baines, R., \& Seaman, P. (2012). Meta-analysis of food safety training on hand hygiene knowledge and attitudes among food handlers. [Meta-Analysis

Research Support, Non-U.S. Gov't

Review]. J Food Prot, 75(4), 793-804. doi: 10.4315/0362-028X.JFP-11-502

UNIDO. (2002). The integrated program for Lebanon to enhance the competitiveness of the Lebanese industry and its integration in the global market Food Safety Panel Progress Report.

Walker, E., Pritchard, C., \& Forsythe, S. (2003). Food handlers' hygiene knowledge in small food businesses. Food Control, 14(5), 339-343. doi: http://dx.doi.org/10.1016/S09567135(02)00101-9 
Investigating a link of two different food business management contexts to the food safety knowledge, attitudes and practices of food handlers in Beirut

Table 1

Mean scores of food safety knowledge of food handlers grouped by experience, position and type of operation

\begin{tabular}{lccc}
\hline Groups & N & Mean Score $^{1}$ & Std. Deviation $^{-}$ \\
\hline Previous food safety training & & & \\
-Yes & 34 & 62.5 & 21.7 \\
-No & 46 & 52.2 & 19.6 \\
Experience & & & \\
- $\geq 10$ yrs. experience & 33 & 64.4 & 18.7 \\
- <10 yrs. experience & 47 & 51.1 & 20.9 \\
Position & & & \\
- Executive/Head Chef & 30 & 63.5 & 20.0 \\
-Assistant Chef/Cook & 44 & 52.3 & 21.0 \\
Food service operations & & & \\
- Corporate & 29 & 64.0 & 22.2 \\
- Sole proprietor & 51 & 52.4 & 19.2 \\
\hline
\end{tabular}

${ }^{1} 100$ point scale $(\mathrm{n}=80)$

Means were significantly different within groups at $\mathrm{p}<0.05$ 


\section{Table 2}

The total percentage of correct answers ${ }^{1}$ given by trained and untrained food handlers to questions on contamination and cross-contamination

\begin{tabular}{|c|c|c|c|c|}
\hline Question & Answers ${ }^{1}$ & $\begin{array}{l}\text { Trained }^{2} \\
\text { N }(\%)\end{array}$ & $\begin{array}{l}\text { Untrained }^{3} \\
\text { N }(\%)\end{array}$ & $\begin{array}{l}\text { Total }^{4} \\
\text { N }(\%)\end{array}$ \\
\hline $\begin{array}{l}\text { Where should we place thawing } \\
\text { meat in the chiller? }\end{array}$ & In the lowest rack & $24(52.2)$ & $22(47.8)$ & $46(57.5)$ \\
\hline Why? & $\begin{array}{l}\text { To avoid dripping (cross- } \\
\text { contamination) }\end{array}$ & $12(50.0)$ & $12(50.0)$ & $24(48.0)^{*}$ \\
\hline $\begin{array}{l}\text { Where in the cooling unit that } \\
\text { contains fresh meats would you } \\
\text { store the prepared salads? }\end{array}$ & $\begin{array}{l}\text { On the highest rack in the } \\
\text { refrigerator }\end{array}$ & $27(42.9)$ & $36(57.1)$ & $63(79.0)$ \\
\hline $\begin{array}{l}\text { After using the knife for } \\
\text { cutting raw meat, it should be }\end{array}$ & $\begin{array}{l}\text { Thoroughly washed and } \\
\text { disinfected }\end{array}$ & $26(54.2)$ & $22(45.8)$ & $48(60.0)$ \\
\hline $\begin{array}{l}\text { Should raw and cooked foods be } \\
\text { separated? }\end{array}$ & Yes & $33(43.4)$ & $43(56.6)$ & $76(95.0)$ \\
\hline Why? & To avoid cross- contamination & $26(55.3)$ & $21(44.7)$ & $47(61.8)^{*}$ \\
\hline $\begin{array}{l}\text { Which of the following are most } \\
\text { likely to cause bacterial } \\
\text { contamination }\end{array}$ & $\begin{array}{l}\text { Food handlers, insects and raw } \\
\text { materials }\end{array}$ & $19(48.7)$ & $20(51.3)$ & $39(48.8)$ \\
\hline
\end{tabular}


Table 3

Mean scores of respondents' self-reported food safety practices

\begin{tabular}{lccc}
\hline \multicolumn{1}{c}{ Groups } & N & Mean $^{1}$ & $\begin{array}{c}\text { Std. } \\
\text { Deviation }\end{array}$ \\
\hline Food service operations & & & \\
-Corporate-managed & 29 & 67.9 & 13.6 \\
-Entrepreneurs-managed & 51 & 57.6 & 12.2 \\
Training & & & \\
-Trained Food Handlers & 34 & 66.4 & 10.7 \\
-Untrained Food Handlers & 46 & 57.6 & 14.3 \\
& & & \\
\hline${ }^{1}$ 100 point scale (n=80 ) & & \\
Means were significantly different within groups at $\mathrm{p}<0.01$ &
\end{tabular}


Table 4

The frequency of temperature control and cross-contamination preventive practices by type of management

\begin{tabular}{|c|c|c|c|}
\hline Self-reported practices & Frequency & $\begin{array}{c}\text { Corporate- } \\
\text { managed }^{1} \\
N(\%) \\
\end{array}$ & $\begin{array}{c}\text { Sole } \\
\text { Proprietor }^{2} \\
\text { N }(\%) \\
\end{array}$ \\
\hline \multirow{5}{*}{$\begin{array}{l}\text { Do you measure the temperature of } \\
\text { received frozen and fresh meat } \\
\text { products? }\end{array}$} & never & $7(26.9)$ & $43(89.6)$ \\
\hline & rarely & $(0.0)$ & $(0.0)$ \\
\hline & sometimes & $(0.0)$ & $(0.0)$ \\
\hline & often & $3(11.5)$ & $1(2.1)$ \\
\hline & always & $16(61.5)$ & $4(8.3)$ \\
\hline \multirow{5}{*}{$\begin{array}{l}\text { Do you take measurements of the } \\
\text { cooler and freezer on your premises? }\end{array}$} & never & $8(29.6)$ & $41(83.7)$ \\
\hline & rarely & $(0.0)$ & $(0.0)$ \\
\hline & sometimes & $(0.0)$ & $(0.0)$ \\
\hline & often & $1(3.7)$ & $2(4.1)$ \\
\hline & always & $18(66.7)$ & $6(12.2)$ \\
\hline \multirow{5}{*}{$\begin{array}{l}\text { Do you measure the temperature of } \\
\text { food during cooking? }\end{array}$} & never & $8(33.3)$ & 43(89.6) \\
\hline & rarely & $(0.0)$ & $(0.0)$ \\
\hline & sometimes & $4(16.7)$ & $2(4.2)$ \\
\hline & often & $2(8.3)$ & $1(2.1)$ \\
\hline & always & $10(41.7)$ & $2(4.2)$ \\
\hline \multirow{5}{*}{$\begin{array}{l}\text { Do you measure the temperature of } \\
\text { food during reheating and cooling? }\end{array}$} & never & $10(41.7)$ & $45(91.8)$ \\
\hline & rarely & $(0.0)$ & $(0.0)$ \\
\hline & sometimes & $(0.0)$ & $(0.0)$ \\
\hline & Often & $(0.0)$ & $2(4.1)$ \\
\hline & Always & $14(58.3)$ & $2(4.1)$ \\
\hline \multirow{5}{*}{$\begin{array}{l}\text { Do you disinfect cutting boards and } \\
\text { utensils used on premises? }\end{array}$} & never & $3(11.5)$ & $27(56.3)$ \\
\hline & rarely & $(0.0)$ & $(0.0)$ \\
\hline & sometimes & $(0.0)$ & $1(2.1)$ \\
\hline & Often & $1(3.8)$ & $1(2.1)$ \\
\hline & Always & $22(84.6)$ & 19(39.6) \\
\hline
\end{tabular}

${ }^{1}$ The percentage of respondents' answers from sole proprietor-owned food businesses

${ }^{2}$ The percentage of respondents' answers from corporate-owned food businesses 
Table 5

The mean scores of respondents' self-reported practices on temperature control and disinfection is related to the type of employer

\begin{tabular}{lccccc}
\hline Question & $\begin{array}{c}\text { Management } \\
\text { type }\end{array}$ & N & $\begin{array}{c}\text { Mean } \\
\text { score }^{1}\end{array}$ & $\begin{array}{c}\text { Std. } \\
\text { Deviation }\end{array}$ & $\begin{array}{c}\text { Std. Error } \\
\text { Mean }\end{array}$ \\
\hline $\begin{array}{l}\text { Do you measure the } \\
\text { temperature of received } \\
\text { frozen and fresh meat } \\
\text { products? }\end{array}$ & Corporate & 26 & $3.81^{\mathrm{a}}$ & 1.8 & .34 \\
$\begin{array}{l}\text { Do you take measurements of } \\
\text { the cooler and freezer on your } \\
\text { premises? }\end{array}$ & Sole proprietor & 48 & $1.40^{\mathrm{a}}$ & 1.2 & .17 \\
$\begin{array}{l}\text { Do you measure the } \\
\text { temperature of food during }\end{array}$ & Cole proprietor & 49 & $1.61^{\mathrm{b}}$ & 1.4 & .20 \\
$\begin{array}{l}\text { cooking? } \\
\begin{array}{l}\text { Do you measure the } \\
\text { temperature of food during } \\
\text { reheating and cooling? }\end{array}\end{array}$ & Sole proprietor & 48 & $1.31^{\mathrm{c}}$ & 1.0 & .14 \\
$\begin{array}{l}\text { Do you disinfect cutting } \\
\text { boards and utensils used on } \\
\text { premises? }\end{array}$ & Sole proprietor & 49 & $1.29^{\mathrm{d}}$ & 1.0 & .14 \\
\hline
\end{tabular}

${ }^{1}$ Mean score on a five-point Likert rating scale

Means were significantly different within groups at $\mathrm{p}<0.05$ 
Table 6

The mean score of food handlers 'beliefs on statements related to food safety practices

\begin{tabular}{|c|c|c|c|c|}
\hline & Management & $\mathbf{N}$ & Mean & $\begin{array}{c}\text { Std. } \\
\text { Deviation }\end{array}$ \\
\hline \multirow{2}{*}{ 1-Training in food safety is essential to my work } & Corporate & 29 & 3.00 & 0.00 \\
\hline & Sole Proprietor & 50 & 3.00 & 0.00 \\
\hline 2- There is all the support that facilitates performing my & Corporate & 29 & $2.83^{\mathrm{a}}$ & 0.46 \\
\hline job according to food safety principles & Sole Proprietor & 50 & $2.42^{\mathrm{a}}$ & 0.85 \\
\hline \multirow{2}{*}{ 3- Jewellery should not be worn in the kitchen } & Corporate & 29 & $2.93^{\mathrm{b}}$ & 0.37 \\
\hline & Sole Proprietor & 50 & $2.40^{\mathrm{b}}$ & 0.88 \\
\hline 4-Using cap, masks, protective gloves, and adequate & Corporate & 29 & 3.00 & 0.00 \\
\hline clothing reduces the risk of food contamination & Sole Proprietor & 50 & 2.92 & 0.34 \\
\hline 5- The staff are provided with hand-washing sinks with & Corporate & 29 & $2.93^{\mathrm{c}}$ & 0.37 \\
\hline soaps and paper towels. & Sole Proprietor & 49 & $2.24^{\mathrm{c}}$ & 0.97 \\
\hline \multirow{2}{*}{$\begin{array}{l}\text { 6- When cooking and reheating food, measuring internal } \\
\text { food temperature is important }\end{array}$} & Corporate & 29 & $2.86^{\mathrm{d}}$ & 0.44 \\
\hline & Sole Proprietor & 50 & $2.18^{\mathrm{d}}$ & 0.98 \\
\hline 7- Raw foods should be kept separately from cooked & Corporate & 29 & 2.86 & 0.51 \\
\hline foods & Sole Proprietor & 49 & 2.94 & 0.31 \\
\hline 8 - It is important to know the temperature of the & Corporate & 28 & 2.96 & 0.19 \\
\hline refrigerator to reduce the risk of food safety & Sole Proprietor & 49 & 3.00 & 0.00 \\
\hline \multirow{2}{*}{$\begin{array}{l}\text { 9- It is not appropriate to thaw frozen food on the kitchen } \\
\text { counter prior to preparation. }\end{array}$} & Corporate & 29 & $2.76^{\mathrm{e}}$ & 0.63 \\
\hline & Sole Proprietor & 50 & $2.40^{\mathrm{e}}$ & 0.92 \\
\hline 10- We can keep ready to eat meat dishes and meat & Corporate & 28 & 1.21 & 0.63 \\
\hline $\begin{array}{l}\text { containing salads for longer than } 2 \text { hours at body } \\
\text { temperature }\end{array}$ & Sole Proprietor & 50 & 1.42 & 0.81 \\
\hline \multirow{2}{*}{ 11- Improper storage of foods may be hazardous to health } & Corporate & 27 & 2.96 & 0.19 \\
\hline & Sole Proprietor & 50 & 3.00 & 0.00 \\
\hline 12- Food-services staff with abrasion or cuts on fingers or & Corporate & 29 & 2.38 & 0.90 \\
\hline $\begin{array}{l}\text { hands should not touch unwrapped foods and use easily } \\
\text { detectable plasters. }\end{array}$ & Sole Proprietor & 50 & 2.10 & 0.97 \\
\hline 13- Food handlers should not prepare food when & Corporate & 29 & 2.86 & 0.51 \\
\hline coughing or having diarrhoea & Sole Proprietor & 49 & 2.71 & 0.68 \\
\hline 14- I believe that a sanitizing agent should be used to & Corporate & 28 & 2.82 & 0.55 \\
\hline $\begin{array}{l}\text { clean surfaces on which raw and cooked foods are } \\
\text { prepared }\end{array}$ & Sole Proprietor & 50 & 2.84 & 0.51 \\
\hline 15- After handling raw meat or poultry, I should always & Corporate & 28 & 2.86 & 0.52 \\
\hline wash my hands with soap and water. & Sole Proprietor & 50 & 2.92 & 0.39 \\
\hline
\end{tabular}

${ }^{1}$ Mean score on a three-point Likert rating scale (1= Disagree to $3=$ Agree)

Means with the same superscript letter are significantly different at $\mathrm{P}<0.05$ 


\section{Investigating a link of two different types of food business management to the food safety knowledge, attitudes and practices of food handlers in Beirut, Lebanon}

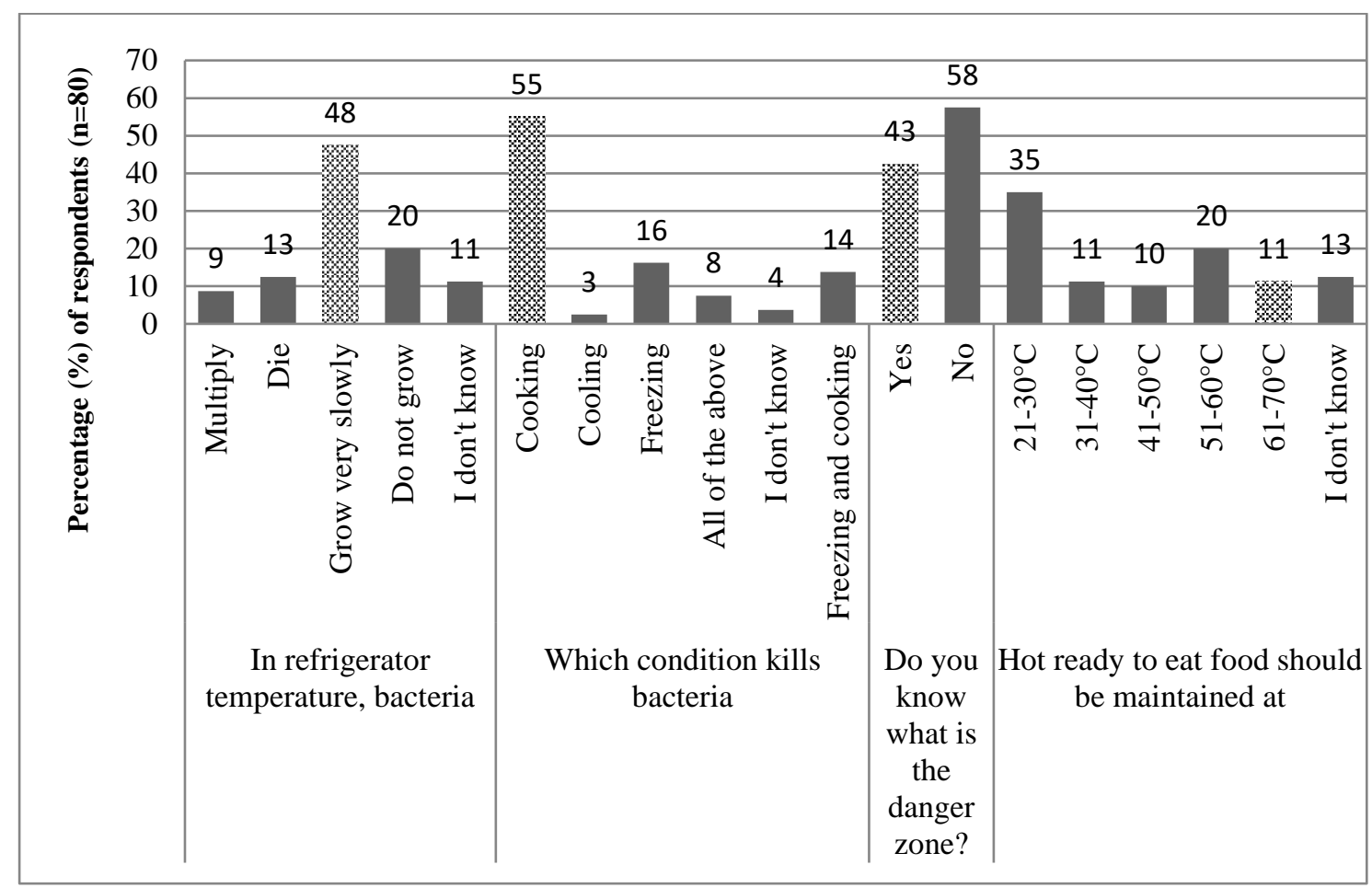

Figure. 1 The response of food handlers (percentage) to multiple choice questions on the safe storage and temperature of foods. Pattern- filled column represents correct answers 
Disagree $\quad$ Agree

After handling raw meat or poultry, I should always wash my hands with soap and water.

I believe that a sanitizing agent should be used to clean surfaces on which raw and cooked foods are prepared

Food handlers should not prepare food when coughing or having diarrhoea

Food-services staff with abrasion or cuts on fingers or hands should not touch unwrapped foods and use...

Improper storage of foods may be hazardous to health

We can keep ready to eat meat dishes and meat containing salads for longer than 2 hours at body.

It is not appropriate to thaw frozen food on the kitchen counter prior to preparation.

Raw foods should be kept separately from cooked foods

When cooking and reheating food, measuring internal food temperature is important

The staff are provided with hand-washing sinks with soaps and paper towels.

Jewellery should not be worn in the kitchen

Using cap, masks, protective gloves, and adequate clothing reduces the risk of food contamination

There is all the support that facilitates performing my job according to food safety principles

Training in food safety is essential to my work

I consider the food I prepare safe for consumers

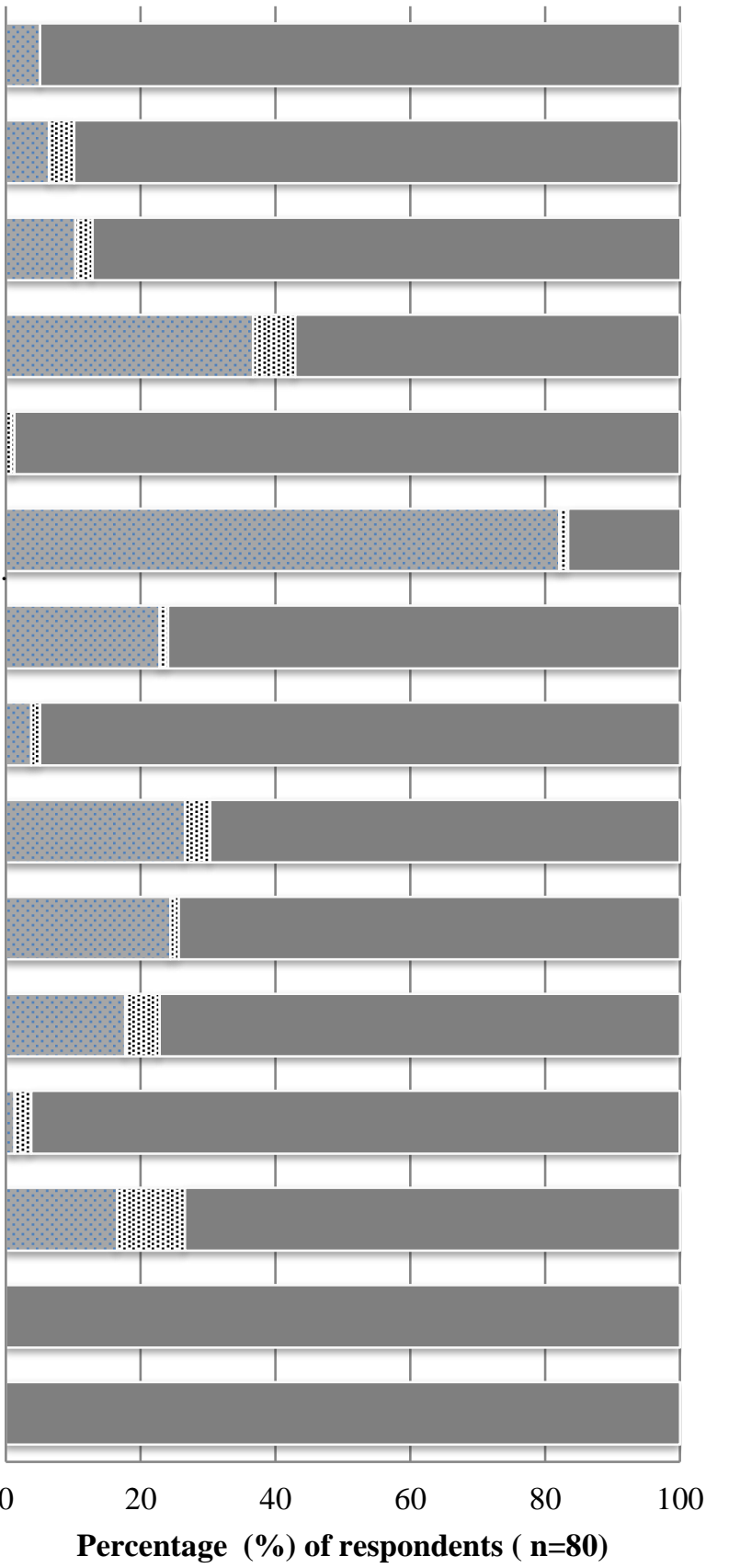

Figure.2 The response of food handlers (percentage) to belief statements related to food safety practices 


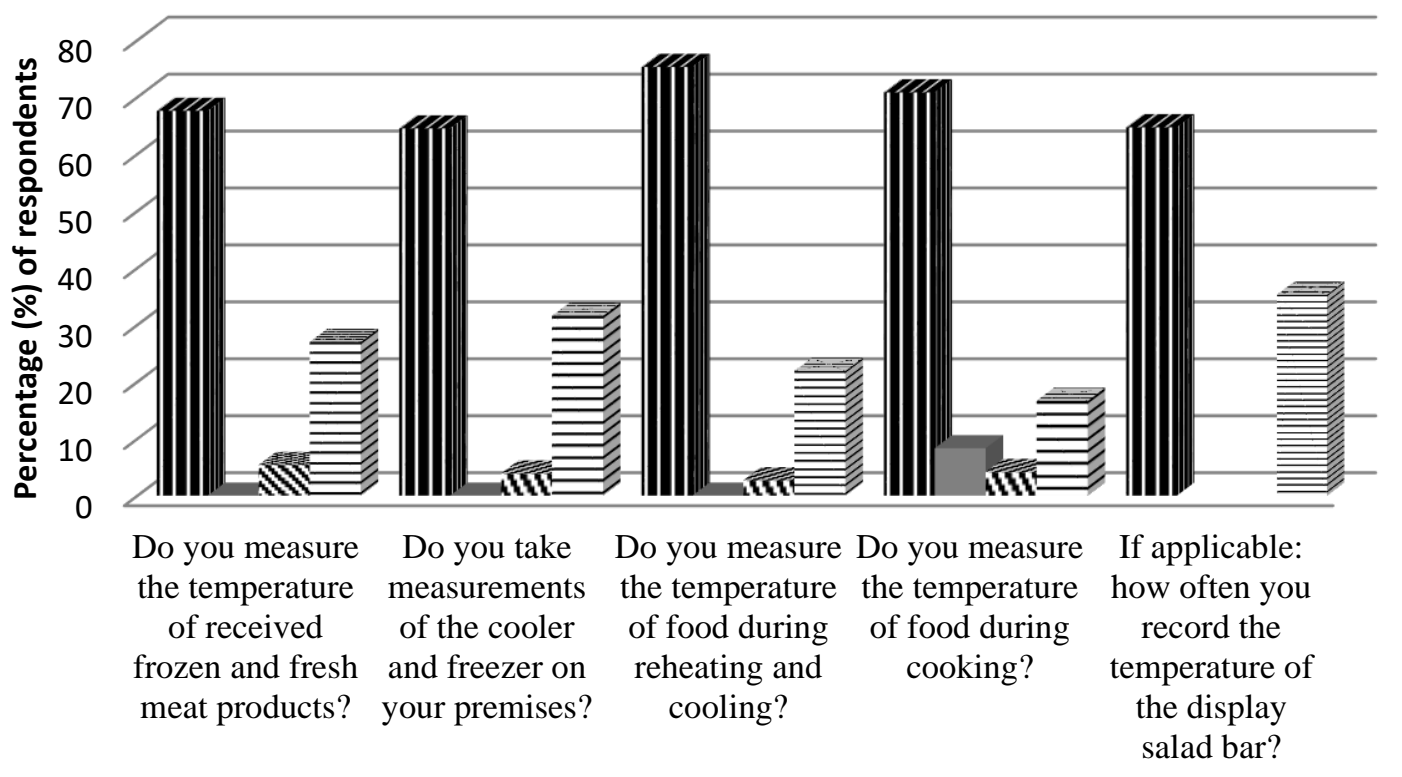

III Never $\square$ Sometimes $\approx$ Often $\equiv$ Always

Figure. 3 Food handlers' self-reported practices related to monitoring of temperatures 